\title{
Transcutaneous oxygen tension during exercise in patients with claudication
}

\author{
T A H HOLDICH， P J REDDY， R T WALKER， J A DORMANDY
}

\begin{abstract}
Transcutaneous oxygen tension $\left(\mathrm{TcPo}_{2}\right)$ was monitored during maximal exercise in 10 patients with stable moderate to severe claudication. The $\mathrm{TcPo}_{2}$ fell by $16 \%$ at the onset of claudication and $32 \%$ at the maximum walking distance. On resting this decrease reached a maximum of $66 \%$ roughly four minutes after exercise. This was followed by a steady recovery. The percentage changes were reproducible in each patient and were appreciably different from the $\mathrm{TcPo}_{2}$ exercise profiles of normal healthy volunteers.

$\mathrm{TcPO}_{2}$ monitoring during exercise is a simple, reproducible, cheap, and useful technique for assessing claudication and compares favourably with other techniques used to quantify this condition.
\end{abstract}

\section{Introduction}

As quantitative assessment of intermittent claudication is complicated, unreliable, and expensive it is difficult to assess objectively the clinical course of claudication or the effects of any treament. The variety of techniques suggests their individual shortcomings. Invasive methods include the use of muscle $\mathrm{pH}$ and oxygen pressure electrodes and electromagnetic flowmeters, Doppler velocitimetry, dilution techniques, and isotope clearance studies. Non-invasive methods include venous occlusion or impedance plethysmography and duplex Doppler scanning. In addition the arterial lumen may be visualised by angiography or digital subtraction angiography and the limb temperature, venous blood oxygenation, and foot systolic blood pressure measured ${ }^{14}$; only the last of these methods has gained any widespread clinical acceptance.

Department of Vascular Surgery, St James's Hospital, London SW12 T A H HOLDICH, MB, BS, research fellow P J REDDY, FRCs, research registrar R T WALKER, FRCS, surgical registrar J A DORMANDY, FRCS, consultant surgeon

Correspondence to: $\mathrm{Mr}$ Dormandy.
Doppler systolic ankle pressures indexed against brachial blood pressure provide a quantitative assessment but are associated with some important problems. Arteries may be difficult to find and their walls may be calcified and incompressible. At rest there may be little arterial pressure gradient until stenosis reaches $70-80 \%$, whereas minimal stenoses may cause claudication. As it is impossible to use a Doppler flowmeter while walking, pressures after exercise are sometimes measured instead. ${ }^{\circ}$ Although such measurements show characteristic changes, in practice it is difficult to measure brachial and ankle pressures simultaneously and as soon as the patient has stopped exercising. Even a few seconds' difference in the delay before the first reading may result in considerable inaccuracies.

We therefore studied the use of the transcutaneous oxygen monitor, originally devised for neonatal monitoring, in assessing patients with claudication. Although other groups have carried out similar studies in patients at rest, ${ }^{,}$the use of the transcutaneous oxygen monitor during exercise seems more relevant in the assessment of intermittent claudication.

\section{Patients and methods}

In the study we used a Hewlett Packard model 78850A oxygen monitor. The transcutaneous oxygen tension $\left(\mathrm{TcPo}_{2}\right)$ probe is a modified Clark electrode: oxygen is reduced at the platinum cathode to produce a current proportional to the partial pressure of oxygen at the electrode surface. ${ }^{910}$ The probe temperature is thermostatically controlled at $45^{\circ} \mathrm{C}$ to produce maximal arterialisation of the skin circulation and diffusion across it. "To use the apparatus the probe is attached to a double sided adhesive ring and the recording started. It is unobtrusive, causes no discomfort to the patient, and produces a clear, easy to read trace on graded paper both during exercise and at rest.

Measurements were taken in 10 patients with claudication (mean age 67 (range 52-72) years) whose symptoms had not changed for at least six months. All had a thigh to arm pressure index of less than 0.75 measured by strain gauge plethysmography. None could walk at a treadmill speed of 4.5 $\mathrm{km} / \mathrm{h}$ and an incline of $10 \%$ for more than six minutes. Each patient attended the hospital twice, with a one month interval, to test the reproducibility of $\mathrm{TcPO}_{2}$ measurements.

Recordings were made on the chest and $10 \mathrm{~cm}$ below the knee joint, over the tibialis anterior muscle (a position used by other workers ${ }^{1213}$ ). Measurements were made with the patient lying supine, sitting with the leg dependent, and standing (all readings being taken after the trace had 
stabilised). Patients were then exercised on a treadmill at an incline of $10 \%$ at speed individually adapted to their maximum walking distance (eight patients at $4.5 \mathrm{~km} / \mathrm{h}$ and two at $3.0 \mathrm{~km} / \mathrm{h}$ ). They were then rested sitting until the pain had resolved and the $\mathrm{TCPo}_{2}$, had once again reached a steady state. Control measurements were taken similarly from 10 volunteers matched for age (mean age 68 (range 53-81) years) with no symptoms, signs, or history of arterial disease. ${ }^{1+}$

Reproducibility of the results was assessed by the correlation of corresponding values about a line of identity. Comparisons within the groups were carried out between points using the Wilcoxon matched pairs single rank test (significance at $\mathbf{p}<0 \cdot 01$ ). Analysis between the groups at appropriate points was carried out using the Mann-Whitney U test (significance at $\mathrm{p}<0.01)$.

\section{Results}

Both the control group and the group of patients with claudication produced characteristic exercise $\mathrm{TcPO}_{2}$ profiles (fig l). There was no difference between the resting values of either group, but the difference in the percentage change in $\mathrm{TcPO}_{2}$ with exercise was highly significant (table I), giving a much better separation between the two groups (fig 2).

In controls (fig 3 ) the mean (SEM) sitting $\mathrm{TcPO}_{2}$ increased on standing from $72(2) \mathrm{mm} \mathrm{Hg}$ to $75(2) \mathrm{mm} \mathrm{Hg}$. At the start of walking there was a brief fall in the mean (SEM) $\mathrm{TcPO}_{2}$ of 2 (3)\% occurring after the first minute, which recovered rapidly. After exercise there was a rise in $\mathrm{TcPo}_{2}$ to 84 (3) $\mathrm{mm} \mathrm{Hg}$ before a return to resting levels. Control subjects experienced no pain or discomfort during exercise.

In the patients with claudication (fig 4 ) there was no significant difference between chest and leg $\mathrm{TcPo}_{2}$ with the patient prone. On sitting, however, there was a rise from 59 (2) $\mathrm{mm} \mathrm{Hg}$ to 71 (2) $\mathrm{mm} \mathrm{Hg}$, but there was no further

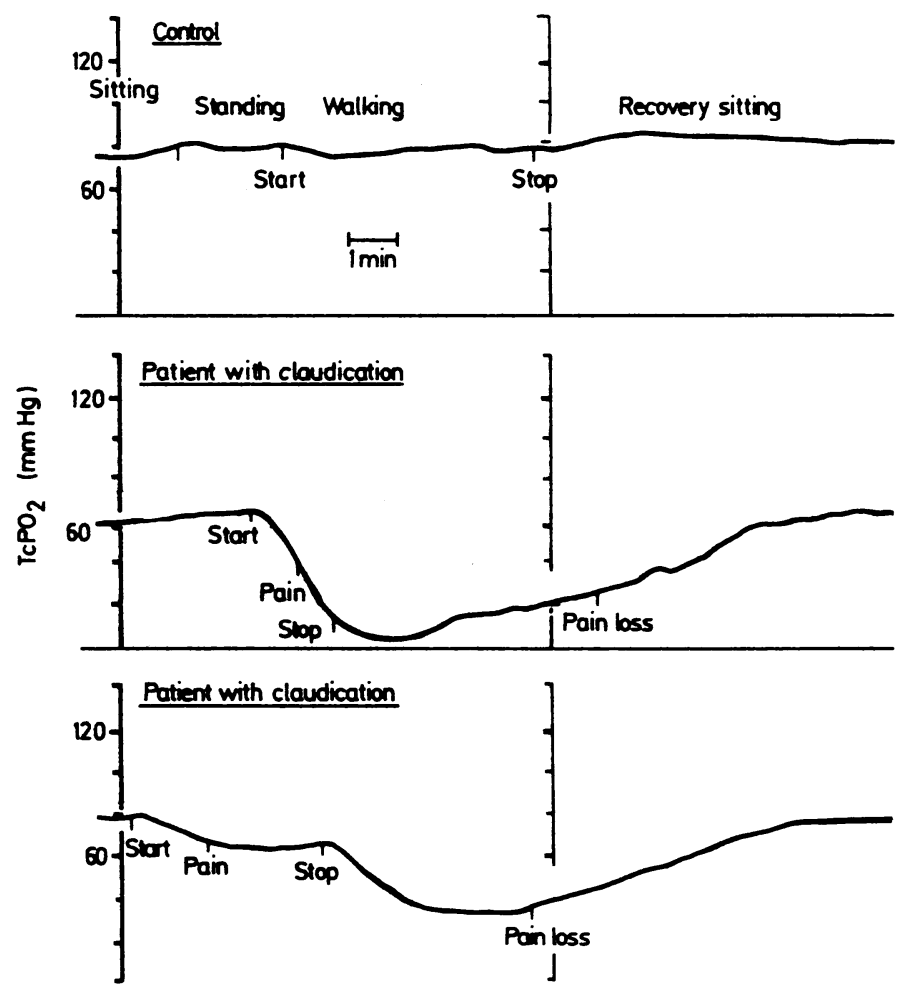

FIG $1-\mathrm{TcPo}_{2}$ profile for controls and two types of profile for patients with claudication.

TABLE I-Comparison between control and claudicant groups

\begin{tabular}{lccc}
\hline $\mathrm{TcPO}_{2}$ measurement & $\mathrm{U}$ & z Value & p Value \\
\hline Standing & 33 & $-1 \cdot 28$ & $\mathrm{NS}$ \\
Sitting & $43 \cdot 5$ & -0.49 & $\mathrm{NS}$ \\
After exercise & 3 & -3.55 & $0 \cdot 0004$ \\
Minimum & 0 & -3.78 & 0.0002 \\
Change at end of exercise $(\%)$ & 2 & -3.63 & 0.0003 \\
\hline
\end{tabular}

increase on standing. During exercise the $\mathrm{TcPO}_{2}$ fell by $16(4) \%$ before the onset of pain. This fall was maintained to the point of maximum exercise, by which time the $\mathrm{TcPo}_{2}$ had fallen by $32(7) \%$. On resting the fall continued, reaching a minimum value with a total drop of $66(6) \% 3 \cdot 5-4 \cdot 5$ minutes after exercise. This was followed by a steady recovery (with loss of pain 43 (9)\% below resting levels) to levels slightly above those found before exercise 11-13 minutes after exercise.
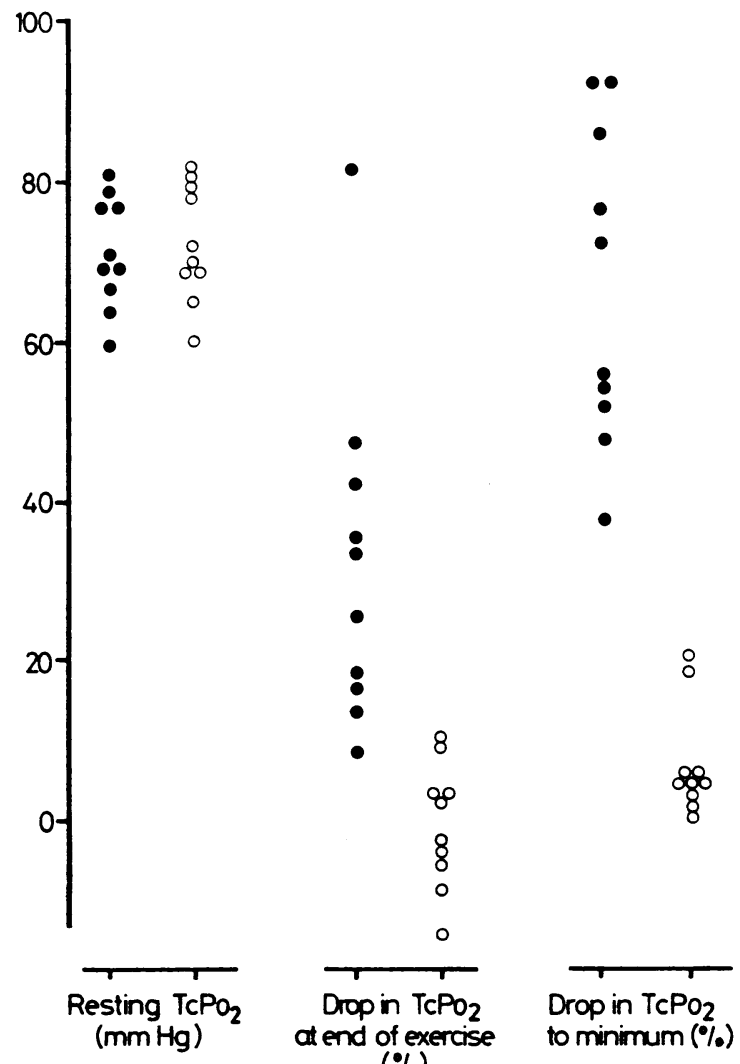

$(\%)$

FIG 2-Comparison of $\mathrm{TcPo}_{2}$ values in controls $(O)$ and patients with claudication (O). Percentage change in $\mathrm{TcPo}_{2}$ with exercise gave a much better separation between the two groups than resting $\mathrm{TcPo}_{2}$.

TABLE II-Reproducibility of $\mathrm{TCPO}_{2}$ values

\begin{tabular}{lccc}
\hline $\mathrm{TcPO}_{2}$ measurement & Correlation & t Value & p Value \\
\hline Chest & 0.19 & 0.545 & $>0.20$ \\
Lying & 0.16 & 0.467 & $>0.20$ \\
Sitting & -0.13 & 0.360 & $>0.20$ \\
Standing & 0.02 & 0.065 & $>0.20$ \\
Change at pain onset (\%) & 0.86 & 4.745 & $<0.01$ \\
Change at end of exercise (\%) & 0.79 & 3.609 & $<0.01$ \\
Minimum & 0.75 & 3.164 & $<0.02$ \\
\hline
\end{tabular}

The reproducibility of resting values in patients with claudication was poor. There was, however, good correlation between monthly readings of percentage changes in $\mathrm{TcPo}_{2}$ during exercise, and even the greatest change in $\mathrm{TcPo}_{2}$ correlated significantly at 0.75 (table II).

The traces for patients with claudication appeared to be of different types (fig 1). In one type the $\mathrm{TcPo}_{2}$ fell at the start of walking and continued to fall steadily throughout exercise, reaching a minimum after exercise. At the other extreme the $\mathrm{TcPo}_{2}$ fell at the start of exercise but then flattened out to give a plateau until the end of exercise. On rest it again fell to give a minimum after exercise followed by recovery.

\section{Discussion}

The main objection against the use of the transcutaneous oxygen monitor in occlusive arterial disease has been that it is affected by 


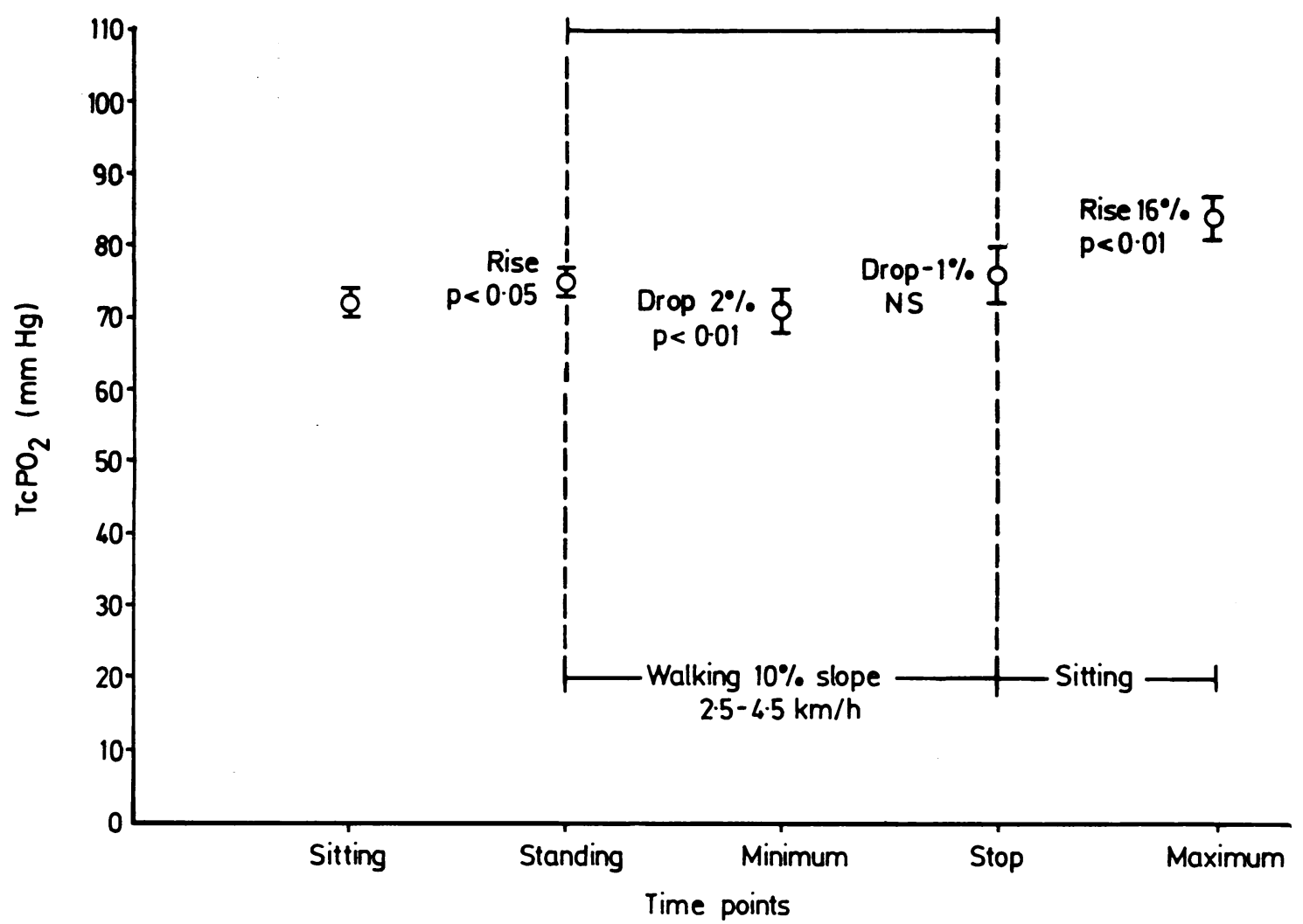

FIG 3-Mean (SEM) walking $\mathrm{TCPO}_{2}$ values for controls on time point scale. Transient changes are seen with exercise.

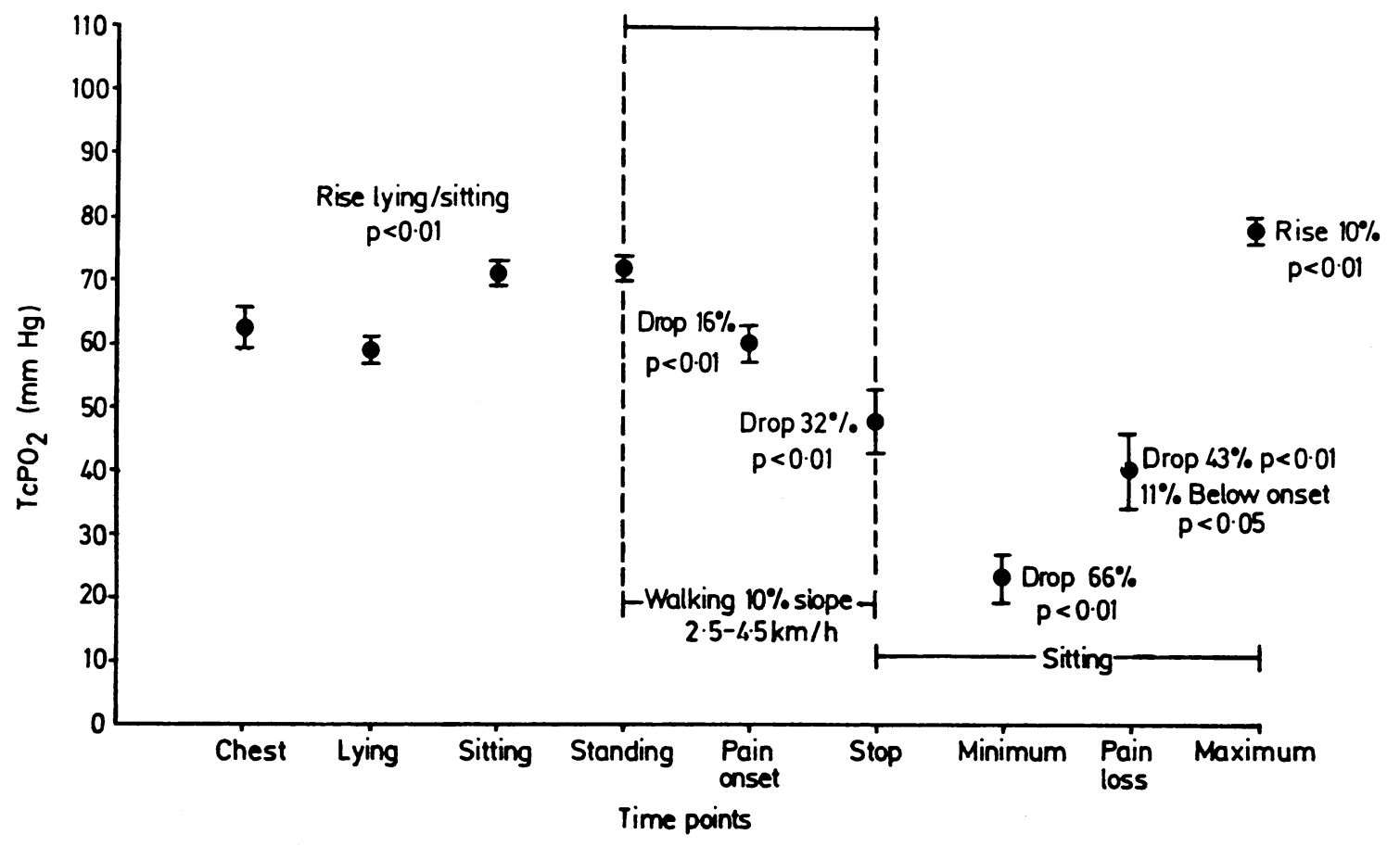

FIG 4-Mean ( $\mathrm{SEM}$ ) walking $\mathrm{TcPo}_{2}$ values for patients with claudication on a time points scale. There is a highly significant fall during exercise, which is maintained on resting giving a minimum after exercise.

too many variables. ${ }^{15}$ The $\mathrm{TcPo}_{2}$ value depends principally on the skin blood flow and the oxygen saturation of the blood. ${ }^{16}$ During walking there is a diversion of available blood flow to exercising muscles sufficient to cause a fall in the ankle systolic pressures in patients with restricted inflow. ${ }^{17}$ In normal subjects the intramuscular oxygen pressure rises with exercise whereas in patients with peripheral vascular disease it falls. ${ }^{18}$ This steal of flow and increased extraction of oxygen will result in a reduced oxygen delivery to the skin and therefore a drop in $\mathrm{TcPO}_{2}$.

In this study resting values and postural changes in $\mathrm{TcPo}_{2}$, both in controls and patients with claudication, agree with published data. ${ }^{13}$ The drop in $\mathrm{TcPo}_{2}$ on exercise in the control group was probably caused by a brief diversion of flow that was quickly compensated by autoregulatory mechanisms. After exercise the 
increased flow persisted for a short length of time giving a temporary rise in $\mathrm{TcPO}_{2}$. In the group of patients with claudication the same process began at the start of walking. The increase in flow, however, was insufficient to compensate for the increased oxygen extraction, and there was a steal of flow from skin to muscle resulting in a persistent fall in $\mathrm{TcPO}_{2}$.

Considering the pattern of change in the patients with claudication, there appeared to be a spectrum between the two types of trace shown in figure 1 . The first type of response may represent the initial fall of the second in patients unable to walk long enough for a plateau to occur. (Indeed, in one patient whose claudication distance subsequently improved dramatically the shape of the trace changed from the first to second type.) In the second type of trace an equilibrium seemed to be reached. The blood flow may be limited by arterial compression within the exercising muscle, which is relieved on rest to allow maximum steal.

The total duration of plethysmographic hyperaemia after occlusion, even in patients with severe claudication, is roughly three to four minutes, ${ }^{i,}$ but the time to recovery of $\mathrm{TcPo}_{2}$ after exercise is more than 10 minutes. This suggests that although the total segmental limb flow returns to resting values quite quickly, the flow distribution and oxygen extraction remain abnormal for much longer. Hence $\mathrm{TcPO}_{2}$ measurements seem to give a better indication of the true duration of the pathophysiological abnormality.

There was no direct or reproducible relation between $\mathrm{TcPo}_{2}$ and the onset and loss of claudication pain. It was apparent, however, that the patients with the worst performance at exercise, and therefore presumably the severest disease, showed the greatest percentage drop in $\mathrm{TcPo}_{2}$ and the longest recovery time.

The monitoring of transcutaneous oxygen at rest has not been a useful assessment of arterial disease, and the overlap between valves for controls and those for patients with claudication has restricted its use to the consideration of amputation sites."' The use of $\mathrm{TcPO}_{2}$ monitoring during exercise, as described in this study, improves reproducibility and gives a good separation between normal and abnormal responses. Exercise $\mathrm{TcPO}_{2}$ is a relevant, reliable, and useful test in patients with claudication, which, in addition to the cost, convenience, accuracy, and ease of operation of the equipment, $\frac{\text { W }}{-}$ makes it an attractive method of quantifying intermittent claudication.

\section{References}

1 Strandnesw DE Jr, Sumner DS. Hemodynamics for surgeons. New York: Grune and Stratton $\mathbb{D}$ Incorporated, 1975

Shepherd JT. Physiolog of the circulation in human limbs in health and disease. London: W' $\mathrm{B}$ Saunders, 1963

Meehan SE Walker W.F. Cuschieri A The effect of chronic ischaemia on tissue $\mathrm{pH}$ of the skin. Eur. Surg Res 1981:3:82-3.

+ Ciroke PA. Heppenstall RB, Littooy FN, et al. The tissue oxygen tension as an index of collateral blood flow during acute arterial occlusion. $S$ Afr $\mathcal{F}$ Surg 1974;12:91-9.

5 Fiddian RV, Byar D, Edwards EA. Factors affecting flow through a stenosed vessel. Arch Surg $\frac{\mathrm{C}}{\sigma}$ 1964;88:83-90.

6 Thulesius $O$. Systemic and ankle blood pressures before and after exercise in patients with arterial $\frac{0}{7}$ insufficiency. Angiolog: 1978;29:374-80.

Lucev JF. Clinical uses of transcutaneous oxvgen monitoring. Adz Pediatr 1981;28:27-56.

8 Franzeck UK, Talke P, Bernstein EF, et al. Transcutaneous PO2 measurements in health and

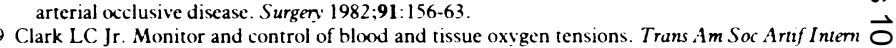

Organs 1956:2:41-54.
10 Huch A, Huch R. Development of the transcutaneous Poz technique into a clinical tool. Birth Defects 1979;XV:5-12.

11 Lubbers D. Cutaneous and transcutaneous $\mathrm{PO}_{2}$ and their measuring conditions. Birth Defects 1979:XV: Cutan

12 Mustapha NM, Redhead RG, Jain SK, et al. Transcutaneous PO2 assessment of the ischemic lower limb; its value in selecting amputation sites. Surg Gynecol Obstet 1983;156:582-40.

13 Hauser CJ, Shoemaker WC. Use of a transcutaneous PO: regional perfusion index to quantify. tissue perfusion in peripheral vascular disease. Ann Surg 1983;197:337-43.

14 Dowd GSE. Linge K. Bentlev G. The effect of age and sex of normal volunters upon the $\mathcal{G}$ transcutancous oxvgen tension in the lower limbs. Clm Phys Physiol .Meas 1983;4:65-8.

I5 I hunstrom A, Stafford M, Severinghaus JW'. A two temperature, two P(): method of estimating the determinants of TcPo. Birth Defects; $\mathrm{XV}: 167-82$.

16 Shoemaker $\mathrm{W}^{\prime}$. Vidyasagar D. Physiological and clinical significance $\mathrm{PTCO}_{2}$ and $\mathrm{PTCCO}_{2} \mathrm{O}$ measurements. Crit Care Med 1981:9:689-90.

17 Strandness DE Jr, Bell JW. An evaluation of hemodynamic response of the claudicating extremity to exercise. Surg Gynecol Obstet 1964;119:1237-42.

18 Jussila EJ, Niinikoski J. Effect of vascular reconstructions on tissue gas tensions in calf muscles of patients with occlusive arterial disease. Ann Chir Gynaecol 1981;70:56-60.

$19 \mathrm{Jageneau}$ AHM. ed. Noninzasize methods of cardiciascular haemodvnamics. Amsterdam: Elsevier North Holland Publishing Companv, 1981.

20 Dowd GSE, Linge $\mathrm{K}$, Bentley G. Transcutaneous $\mathrm{PO}_{2}$ measurements in skin ischaemia. Lancet $1982 ; \mathrm{i}: 48$.

Aciepled 4 April 1986 